REVISTA DE GEOCIÊNCIAS DO NORDESTE

Northeast Geosciences Journal

v. $7, \mathrm{n}^{\circ} 2(2021)$

https://doi.org/10.21680/2447-3359.2021v7n2ID23952

ISSN: 2447-3359

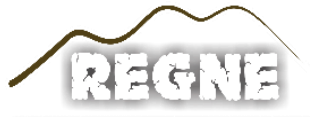

\title{
ANÁLISE PROSPECTIVA DE CORPOS MÁFICOS-ULTRAMÁFICOS ATRAVÉS DE AEROGEOFÍSICA: CASO DE ESTUDO DO VALE DO JACURICI/BAHIA
}

\author{
João Rodrigo Pilla Dias'; Gabriel Bertolini²; \\ Juliana Charão Marques ${ }^{3}$; José Carlos Frantz ${ }^{4}$; \\ Carlos José Sobrinho da Silveira ${ }^{5 ;}$ Natanael \\ Cezário ${ }^{6}$;
}

1 Doutorado em Geologia, Programa de pós-graduação em Geologia, Universidade Federal do Rio Grande do Sul (UFRGS), Porto Alegre/RS, Brasil.

ORCID: https://orcid.org/0000-0002-5147-3305

Email: joaorodrigo.dias@gmail.com

${ }^{2}$ Doutor em Geologia, Instituto de Geociências, Universidade Federal do Rio Grande do Sul (UFRGS), Porto Alegre/RS, Brasil. ORCID: $\underline{\text { https://orcid.org/0000-0002-3873-6190 }}$

Email: gabertol@gmail.com

${ }^{3}$ Doutor em Geologia, Instituto de Geociências, Universidade Federal do Rio Grande do Sul (UFRGS), Porto Alegre/RS, Brasil. ORCID: https://orcid.org/0000-0003-0143-6925

Email: juliana.marques@ufrgs.br

${ }^{4}$ Doutor em Geologia, Instituto de Geociências, Universidade Federal do Rio tgrande do Sul (UFRGS), Porto Alegre/RS, Brasil. ORCID: https://orcid.org/0000-0002-8890-7250

Email: jose.frantz@ufrgs.br

${ }^{5}$ Mestre em Geologia, Secretária do Meio Ambiente (SEMA), Porto Alegre/RS, Brasil.

ORCID: https://orcid.org/0000-0003-4321-6023

Email: carlos-silveira@sema.rs.gov.br

${ }^{6}$ Bacharel em Geologia, Pilar Gold Inc., Itapeci/GO, Brasil.

ORCID: https://orcid.org/0000-0002-8737-3912

Email: natanaelcezario@gmail.com

\section{Resumo}

O Complexo máfico-ultramáfico Jacurici abriga o maior depósito de cromo do Brasil. Esse depósito é caracterizado pela presença de uma camada maciça de cromitito que ocorre em uma única intrusão tectonicamente fragmentada que, atualmente, aflora em diferentes segmentos ao longo de uma faixa N-S. O presente trabalho investiga as características desses corpos através de técnicas de sensoriamento remoto e levantamentos aerogeofísicos, descrevendo as respostas gamaespectrais, sucessibilidade magnética e de relevo dos alvos econômicos. A área de estudo apresenta anomalias magnéticas quando se utilizam filtros de $1^{\text {a }}$ derivada e tilt derivativo do campo magnético total, ao passo que razões eTh/K e eU/Kapresentam as melhores delimitações dos corpos ígneos utilizando o método gamaespectrométrico. As informações apresentadas servem como parâmetro prospectivo na descoberta de novos corpos laterais, a fim de prover guia para a descoberta e análise de corpos similares.

Palavras-chave: Complexo máfico-ultramáfico Jacurici; Prospecção mineral; Geofísica regional.

\section{AIRBORNE GEOPHYSICAL SURVEYING OF MAFIC- ULTRAMAFIC BODIES: A STUDY CASE FROM JACURICI COMPLEX (BAHIA)}

\begin{abstract}
The Jacurici mafic-ultramafic Complex hosts the largest chrome deposit in Brazil. This deposit is characterized by the presence of a massive chromitite layer that occurs in a single intrusion tectonically fragmented that, currently, outcrops in different segments along an $\mathrm{N}-\mathrm{S}$ belt. The present work investigates the characteristics of these bodies through remote sensing techniques and airborne geophysical surveys, describing the geophysical and landform responses of economic targets. The study area presents magnetic anomalies when using $1^{\text {st }}$ derivative filters and tilt derivative of the total magnetic field, whereas eU/K and $\mathrm{eTh} / \mathrm{K}$ ratios define the best delimitations of igneous bodies using the gamma-spectrometric method. The information presented serves as a prospective parameter in the discovery of new lateral bodies in order to provide a guide for the discovery and analysis of similar deposits by Brazil.
\end{abstract}

Keywords: Jacurici mafic-ultramafic complex; Mineral prospecting; Regional geophysics. 


\section{ANÁLISIS PROSPECTIVO DE CUERPOS DE MÁFICOS- ULTRAMÁFICOS MEDIANTE AEROGEOFÍSICA: ESTUDIO DE CASO DE VALE DO JACURICI / BAHIA}

\begin{abstract}
Resumen
El Complejo Máfico-Ultramáfico Jacurici alberga el mayor depósito de cromo de Brasil. Este depósito se caracteriza por la presencia de una capa masiva de cromitita que se presenta en una sola intrusión tectónicamente fragmentada que, actualmente, aflora en diferentes segmentos a lo largo de un cinturón N-S. El presente trabajo investiga las características de estos cuerpos mediante técnicas de teledetección y levantamientos aerogeofísicos, describiendo las respuestas geofísicas y de relieve de los objetivos económicos. El área de estudio presenta anomalías magnéticas al utilizar filtros de $1^{\mathrm{a}}$ derivada y derivada de inclinación del campo magnético total, mientras que las relaciones eU / K y eTh / K definen las mejores delimitaciones de cuerpos ígneos mediante el método gamma-espectrométrico. La información presentada sirve como parámetro prospectivo en el descubrimiento de nuevos cuerpos laterales con el fin de proporcionar una guía para el descubrimiento y análisis de depósitos similares por Brasil.
\end{abstract}

Palabras-clave: Complejo máfico-ultramáfico Jacurici; Prospección mineral; Geofísica regional.

\section{INTRODUÇÃO}

O Complexo Jacurici abriga o maior depósito cromitífero brasileiro (MARINHO et al., 1986), cuja explotação estende-se desde a década de 70 pela FERBASA, com produção atual de, aproximadamente, $300 \mathrm{~T}$ de cromita (35 a $40 \%$ peso de $\mathrm{Cr}_{2} \mathrm{O}_{3}$ ). O cromo (Cr) é um elemento químico com ampla utilização nas áreas de indústria metalúrgica, química e de refratários (KOLELI; DEMIR, 2016). Esse elemento se encontra predominantemente inserido em Cromoespinélio (CLARK, 1978; IRVINE, 1967).

A mineração está localizada no município de Andorinha, na Bahia, pertencente ao território Piemonte Norte do Itapicuru, abrigando aproximadamente 260 mil habitantes (SEPLAN, 2013). Apesar dos avanços sociais obtidos na região nos últimos 20 anos, o território ainda apresenta altos índices de analfabetismo e baixa adesão aos sistemas de saneamento básico (SEPLAN, 2013). Sob essa ótica, empreendimentos industriais, como a mineração, sob a tutela de rígidos protocolos ambientais, servem como vetores econômicos para o desenvolvimento social de regiões de vulnerabilidade humana.

O presente trabalho busca caracterizar e obter guias prospectivos para depósitos associados a rochas máficaultramáficas, utilizando o Complexo Jacurici como exemplo. Sabendo do alto potencial mineral no território brasileiro, o estudo aplicado na área tem potencial de auxiliar na identificação de novos corpos e na delimitação de depósitos conhecidos. Estudos similares foram aplicados na identificação de depósitos minerais, como, por exemplo, o depósito de platinóides e cromo na Província Carajás (FILHO et al., 2007) ou os depósitos associados a corpos ultramáficos do Morro Feio (SILVA; DUQUE; ALVES, 2019) no Brasil. Além disso, técnicas geofísicas têm sido aplicadas para a identificação de prospectos minerais em todo o mundo, como os depósitos sulfetados de Ni$\mathrm{Cu}$ do grupo Longshoushanna China (VAN DER MEER; LIHUI;
BODECHTEL, 1997), as rochas kimberlíticas do oeste da Groenlândia (TUKIAINEN; THORNING, 2005), os depósitos sulfetados a $\mathrm{Ni}-\mathrm{Cu}$ na região Leste de Arunta na Austrália e rochas ultramáficas do Norte da Noruega (KARLSEN; OLESEN, 1996). Para tanto, foram utilizados levantamentos aerogeofísicos regionais - gamaespectrometria e suscetibilidade magnética identificando a intensidade de diferentes tipos de sinais geofísicos nos corpos para classificar a eficácia destes na identificação de corpos máfico-ultramáfico possivelmente ricos em Cr.

\section{CONTEXTO GEOLÓGICO}

\subsection{Geologia Regional}

O Complexo Máfico-ultramáfico do Jacurici integra a porção nordeste do Cráton do São Francisco (Figura 1). Esse cráton é constituído por terrenos Arqueanos a Paleoproterozoicos gnáissicos (migmatíticos-granulíticos) de alto grau e terrenos supracrustais granito-greenstone, recobertos por terrenos Meso a Neoproterozoicos do tipo plataforma continental (OLIVEIRA; MCNAUGHTON; ARMSTRONG, 2010; TEIXEIRA et al., 2010). Especificamente para as rochas do embasamento, os trabalhos na área foram realizados por Oliveira, Mcnaughton e Armstrong (2010) e Silveira et al. (2015). Atualmente, as discussões estão concentradas no posicionamento regional e temporal do magmatismo que compõe o Complexo Jacurici em relação as suas encaixantes, sendo esse assunto motivo de controvérsias. As rochas máfica-últramáficas têm sido interpretadas como intrusivas no Bloco Serrinha (KOSIN et al., 2003; OLIVEIRA; MCNAUGHTON; ARMSTRONG, 2010; OLIVEIRA; CARVALHO; MCNAUGHTON, 2004), no Cinturão Salvador-Curaçá (BARBOSA; SABATÉ, 2003; MISI et al., 2012; TEIXEIRA et al., 2010), ou em ambos (SILVEIRA et al., 2015) durante o Paleoproterozóico.

O trabalho mais recente de mapeamento geológico na área foi realizado pela CPRM (COSTA, 2014). Nessa publicação, a área foi considerada como inserida totalmente no Complexo Santa Luz, de idade mesoarqueana e pertencente ao Bloco Serrinha (Figura 2). As unidades de embasamento descritas são: ortognaisses migmatíticos metassomatizados, ortognaisses migmatíticos tonalíticos a granodiroríticos, mármores calcítico a dolomítico e granada biotita gnaisse. Segundo esse mapa, o Complexo Jacurici está hospedado na unidade de granada biotita gnaisse (3085 $\pm 6 \mathrm{Ma}$, OLIVEIRA et al. 2002), embora em escala de maior detalhe ocorra maior diversidade de litologias. A oeste dessa faixa, ocorrem granitoides intrusivos de idade riaciana, representados pelo Maciço Sienítico Itiúba $(2084 \pm 10 \mathrm{Ma}$, (OLIVEIRA; CARVALHO; MCNAUGHTON, 2004)). As rochas do Cinturão Salvador-Curaçá, representadas pelo Complexo Caraíba (ortognaisses granulíticos, $2695 \pm 12 \mathrm{Ma}$, SILVA et al. 1997) e Complexo Tanque Novo-Ipirá (gnaisses aluminososos, calcissilicáticas, quartzitos e metacalcários), afloram no extremo noroeste da área. Especificamente para as rochas máficas-ultramáficas do Complexo Jacurici, datação U$\mathrm{Pb}$ SHRIMP em zircões realizada em norito indicou idade de $2085 \pm 6 \mathrm{Ma}$, sendo interpretada como relativa à época de cristalização do Jacurici (OLIVEIRA; CARVALHO; MCNAUGHTON, 2004). Todavia, (SILVEIRA et al., 2015) obteve idade U-Pb em zircões por LA-ICP-MS de $2102 \pm 5 \mathrm{Ma}$ 
em metanorito associado ao Complexo Jacurici e concluiu que esta idade seria condizente com os primeiros pulsos do magmatismo máfico-ultramáfico. Entretanto, todas as idades devem ser avaliadas com cautela, considerando que podem, de forma alternativa, estarem relacionadas com o metamorfismo regional.

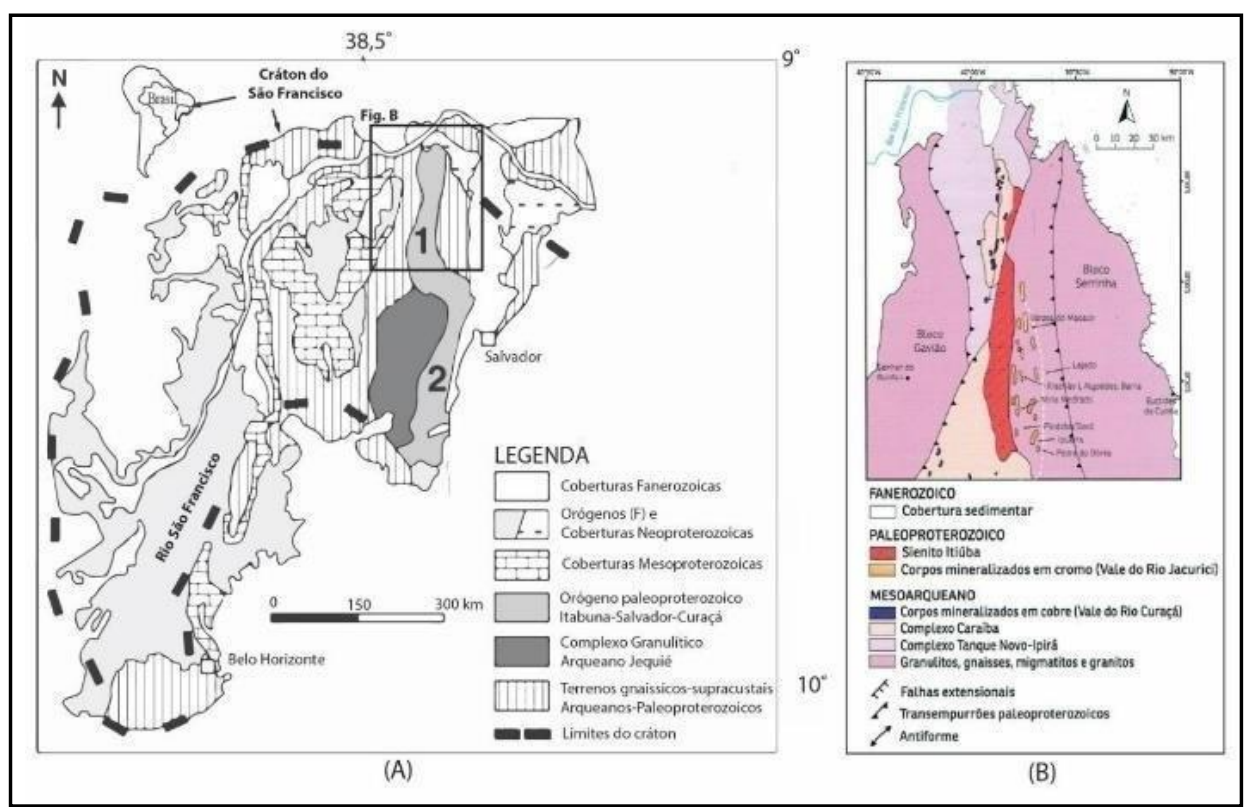

Figura 1 - (A) Mapa do Cráton do São Francisco mostrando os segmentos norte (1) e sul (2) do Orógeno Itabuna-Salvador-Curaçá. (B) Detalhe do segmento norte do Orógeno-Itabuna-Salvador-Curaçá destacando os corpos cromitíferos do Vale do Rio Jacurici. Modificado de MENEZES LEAL; BARBOSA; CORRÊE-GOMES, 2012; OLIVEIRA; MCNAUGHTON; ARMSTRONG, 2010).

A evolução estrutural e metamórfica da área está disponível em poucos trabalhos, e MARINHO et al. (1986) permanece como principal referência. Os seguintes eventos foram relatados: (1) Evento deformacional D1, responsável por dobramentos isoclinais e transposições, tendo como registro a foliação S1 paralela a S0, bem marcada nas rochas supracrustais hospedeiras (Granada Biotita Gnaisse) e nos ortognaisses granodioríticos (G1); (2) Evento deformacional D2, que dobra de forma apertada a isoclinal a foliação $\mathrm{S} 1$ dos gnaisses bandados. Contemporâneo a esse evento, intrudem granodioritos e tonalitos (G2); (3) Evento deformacional D3, responsável pela estruturação do trend regional de direção NNE a NNW. Durante esse evento, ocorre intrusão de rochas graníticas a sieníticas (G3), cujo representante principal é o Sienito Itiúba. Em relação ao metamorfismo, apenas as intrusões G3 teriam sido submetidas ao metamorfismo em fácies anfibolito, as demais estariam metamorfizadas em fácies granulito. Segundo Marinho et al. (1986), o Complexo Máficoultramáfico Jacurici foi posicionado no evento D1, anterior aos ortognaisses granodioríticos (G1).

\subsection{Geologia do Complexo Máfico-Ultramáfico Jacurici}

O Complexo Máfico-Ultramáfico Jacurici (Figura 2) é formado por mais de 15 corpos intrusivos acamadados orientados no sentido N-S. Esse complexo hospeda uma das principais reservas de cromita do Brasil, estimada em mais de $40 \mathrm{Mt}$, explorada, atualmente, pela companhia Mineração Vale do Jacurici S. A., pertencente ao grupo FERBASA. Hospeda também uma mineralização de $\mathrm{Ni}-\mathrm{Cu}$ sulfetada na sua porção norte. O Complexo Jacurici foi estudado em detalhe no segmento central do Complexo (segmento Ipueira-Medrado, BARBOSA de DEUS e VIANA (1982), MARQUES e FILHO (2003), MARQUES et al. (2003), e trabalhos mais recentes investigaram a parte central (segmento Monte Alegre Sul, FRIEDRICH et al. (2020)) e o segmento norte (Várzea do Macaco (DIAS et al., 2014). Destacase, ainda, o trabalho de MARQUES et al. (2017) que faz uma revisão e introduz novas informações sobre o Complexo. Os diversos corpos mineralizados que compõem o Complexo Jacurici possuem diversas características em comum, destacandose uma média de menos de $300 \mathrm{~m}$ de espessura e ocorrência de uma espessa camada de cromitito comum a todos os corpos, denominada de Cromitito Principal. Essa camada tem sido usada como um nível de correlação estratigráfica entre os diferentes segmentos rompidos tectonicamente e permitem estimar que os corpos mineralizados constituíam uma única intrusão anteriormente (MARQUES; FILHO, 2003), embora a dimensão da província magmática seja estimada como muito superior (MARQUES et al., 2017). Os corpos máfico-ultramáficos estão deformados, dobrados, falhados e metamorfizados em fácies anfibolito superior a granulito, embora preservem localmente muitas feições e mineralogia original magmática (BARBOSA DE DEUS; VIANA, 1982; FRIEDRICH et al., 2020; MARQUES et al., 2017; MARQUES; FILHO, 2003). 


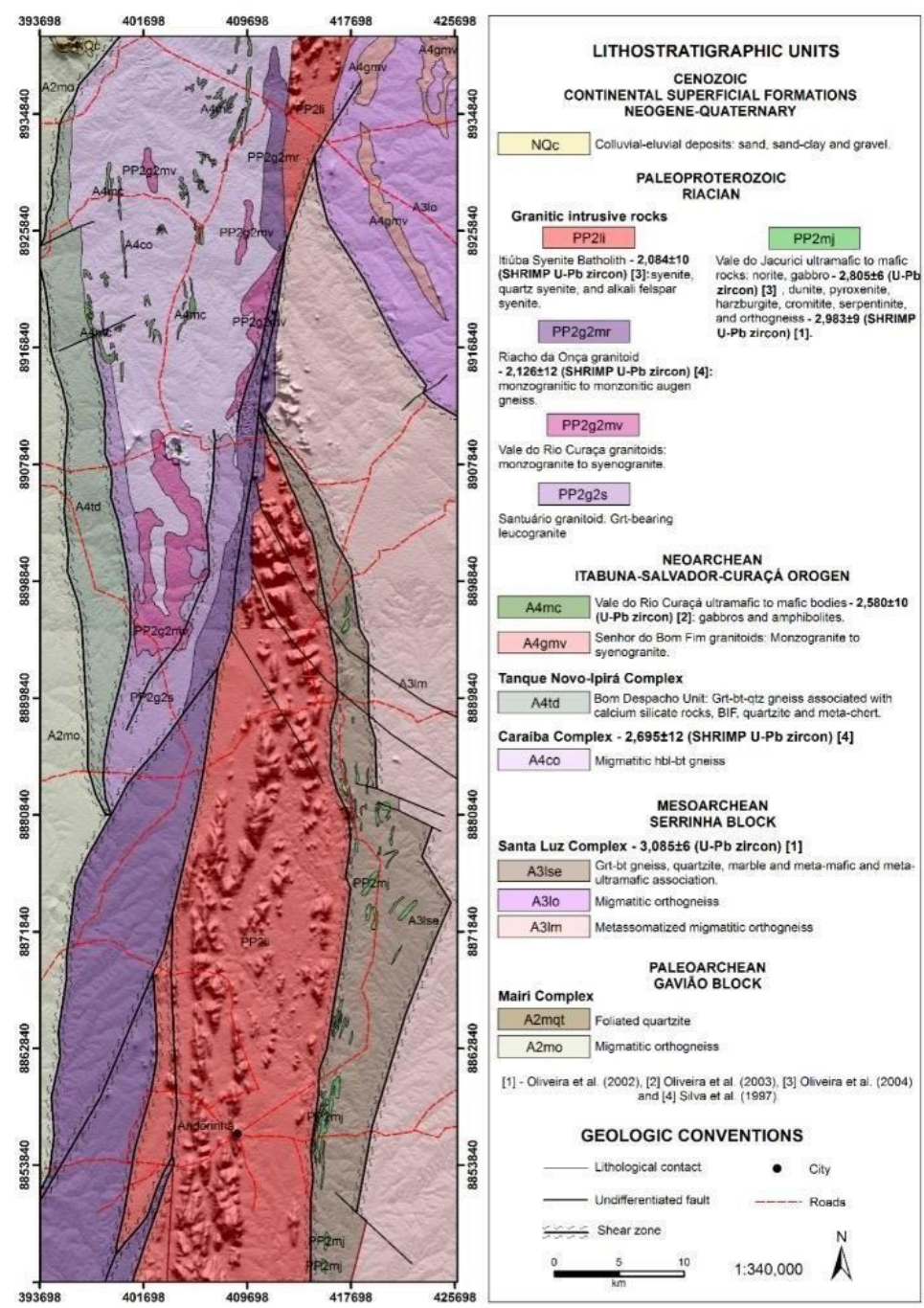

Figura 2 - Mapa Geológico Simplificado das regiões Vale do Jacurici e Vale do Curaçá (a partir de dados de COSTA, 2014).

Marques e Filho (2003) subdividiram a intrusão em 3 zonas principais baseados na composição da rocha no segmento Medrado-Ipueira, sendo da base para o topo: Zona marginal, composta por gabros; Zona Ultramáfica, subdividida nos membros Unidade Ultramáfica Inferior, Camada de Cromitito Principal e Unidade Ultramáfica Superior; e, por fim, Zona Máfica, composta por noritos com proporções variáveis de ortopiroxênio e plagioclásio (Figura 3). Os autores, através da observação da variação críptica em olivina e ortopiroxênio, identificaram uma evolução petrológica complexa (Figura 3). Um regime magmático aberto, com aporte cíclico de magma primitivo na câmara magmática, no intervalo que antecede a formação da Camada de Cromitito Principal foi reconhecido e, após essa camada, um regime fechado marcado por cristalização fracionada ocorre. Abaixo da Camada de Cromitito Principal, ao longo da Unidade Ultramáfica Inferior, foi observado um acréscimo gradual no teor de $\mathrm{Mg}$ dos minerais e, acima dessa camada, ao longo da Unidade Ultramáfica Superior, houve uma rápida evolução em direção a composições mais diferenciadas, ricas em Fe (Figura 3). Isto demonstrou que esta camada maciça de cromitito deve ter se formado a partir de uma mudança drástica durante a evolução magmática. Em relação à mineralização sulfetada, foi observado que os conteúdos de forsterita e Ni nas olivinas são positivamente correlacionados ao longo de toda a estratigrafia do segmento Ipueira-Medrado, o que, somado com a ausência de sulfetos neste local, demonstra que não houve saturação precoce de enxofre no sistema. Isto é um aspecto que favorece a possibilidade de mineralizações sulfetadas na região.

A formação de uma camada tão espessa de cromitito (5-8 m), como a Camada de Cromitito Principal do Complexo Jacurici, é difícil de explicar considerando os modelos atuais. Por essa razão, Friedrich et al. (2020) e Marques et al. (2003) estudaram em 
detalhe a formação dos cromititos e definiram que o intervalo de formação da Camada de Cromitito Principal é caracterizado por mudanças importantes nas condições físico-químicas da câmara magmática. Tais mudanças são marcadas pela troca de regime magmático e por um aumento na quantidade de anfibólio durante e após a referida camada. Essas informações, juntamente com dados de química mineral e dados isotópicos de $\mathrm{Nd}$ e Os, forneceram fortes evidências de que o cromitito possa ter se formado a partir da assimilação crustal por um magma bastante primitivo rico em $\mathrm{Mg}$ e $\mathrm{Cr}$ (MARQUES et al., 2003).

Dados de geoquímica de elementos traço mostraram que tanto a Unidade Ultramáfica Superior quanto a Unidade Ultramáfica Inferior cristalizaram a partir de magmas parentais similares. Esse magma era enriquecido em LREE e LILE, depletado em Ta e enriquecido em $\mathrm{Zr}$. Essas características, juntamente com outros fatores (e.g. grande quantidade de fluidos), sugerem duas possibilidades: (1) o magma parental era similar a um basalto alto-Mg ou komatiíto gerado por fusão parcial de manto convectivo, subsequentemente enriquecido em LREE e LILE por interação com algum componente crustal antigo arqueano; ou, (2) o magma parental era proveniente de um antigo manto litosférico subcontinental metassomatizado, provavelmente as raízes de um Cráton Arqueano. Nesse último caso, o magma parental não estaria contaminado por material crustal antes de intrudir, com o enriquecimento em LILE e LREE e os baixos conteúdos de Ta e altos de $\mathrm{Zr}$ sendo explicados por alguma fase residual rica em $\mathrm{Ti}$ no manto enriquecido (Marques et al., 2003).

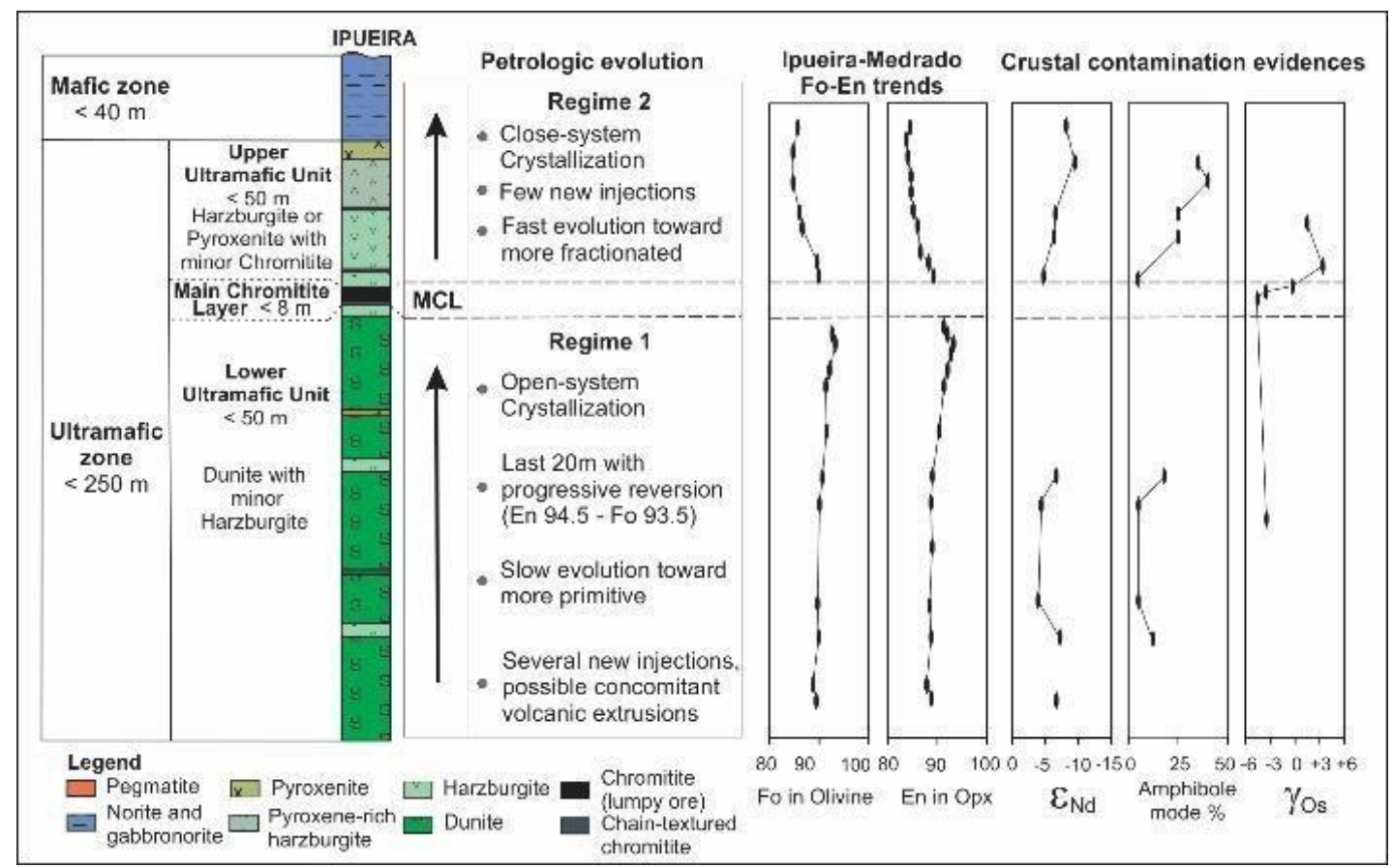

Figura 3 - Variações estratigráficas de $(\mathrm{Ce} / \mathrm{Sm}) \mathrm{N}, \varepsilon N d$, proporção modal de anfibólio e $\gamma$ Os no segmento sul de Ipueira-Medrado. As variações estratigráficas de (Fo) em olivina e (En) e ortopiroxênio também estão representadas. LUU, Unidade Ultramáfica Inferior; MCL, Cromitito Principal; UUU, Unidade Ultramáfica Superior (Marques et al., 2003)

Marques et al. (2003) conduziram, juntamente com os estudos de elemento traço, um cuidadoso estudo isotópico de $\mathrm{Nd}$ e Os. Os resultados mostraram valores iniciais $\varepsilon_{\mathrm{Nd}}$ negativos para todas as amostras, sendo as mais negativas aquelas enriquecidas em anfibólio. Tais dados são consistentes com um magma parental originalmente contaminado por material crustal, ou derivado de uma antiga fonte mantélica de litosfera subcontinental metassomatizada e enriquecida em LREE. Todavia, valores de $\gamma_{O s}$ negativos abaixo do Cromitito Principal e positivos acima desta camada, e na Unidade Ultramáfica Superior, aliados a valores de $\varepsilon_{\mathrm{Nd}}$ mais negativos nas amostras com mais anfibólio abundantes nestes intervalos, sugerem que o magma foi contaminado na câmara magmática durante a cristalização exatamente no intervalo que forma o cromitito (Figura 3).
Portanto, o provável magma parental para o Complexo Jacurici é um alto-Mg (basalto picrítico ou tipo-U do Complexo Stillwater) gerado a partir de um manto litosférico subcontinental depletado em Re (antigo), com a presença de uma fase residual rica em $\mathrm{Ti}$, ou metassomatizado por um fluido deficiente em HFSE. O magma foi posteriormente contaminado com até $30 \%$ de crosta continental arqueana, possivelmente dentro da câmara magmática, desencadeando a cristalização do Cromitito Principal (MARQUES et al., 2003).

Entretanto, a espessura anômala (até $8 \mathrm{~m}$ ) do Cromitito Principal constitui um grande problema de balanço de massa. Levando-se em consideração o teor de $\mathrm{Cr}_{2} \mathrm{O}_{3}$ reportado para magmas máficos e o volume de rocha silicática observado, um cromitito tão espesso só poderia ser explicado se a intrusão 
atuasse como um conduto, no qual flui um grande volume de magma. Dessa forma, entender melhor o contexto regional e avaliar as demais expressões magmáticas possivelmente correlatas a esse magmatismo constitui importância crucial para entendimento do depósito de cromo e pode auxiliar na prospecção de novos alvos.

\section{MATERIAIS E MÉTODOS}

Os dados da área de estudo foram obtidos junto à Companhia Baiana de Pesquisa Mineral (CBPM), referente ao levantamento aerogeofísico do setor Riacho Seco-Andorinha. Foram levantados um total de $11030 \mathrm{~km}^{2}$, pela empresa LASA Engenharia e Prospecções S. A. Para tanto, foram utilizados aeronave com asa fixa, sistema acoplado com sensores de gamaespectrometria e magnético. O levantamento da área consistiu em transectos a cada $250 \mathrm{~m}$ no sentido E-O, com linhas de controle a cada $2500 \mathrm{~m}$ no sentido N-S, com altura de voo de $250 \mathrm{~m}$. Os sensores geofísicos coletam amostras a cada 0.1 e $1.0 \quad \mathrm{~s}$ (magnético e gamaespectrometria, respectivamente), com sensor de vapor de Cs e resolução de $0.001 \mathrm{nT}$ (magnético) e 256 canais espectrais (gamaespectrometria) (LASA, 2002). A delimitação geológica dos corpos do Jacurici foi retirada do levantamento geológico do Estado da Bahia (CBPM/CPRM, 2003), ainda que, em detalhe, o Complexo Jacurici seja caracterizado por vários segmentos descontínuos inclusos na área de localização (Figura 4). Os segmentos aqui denominados de norte e sul incluem os corpos na área de Monte Alegre Sul e Ipueira-Medrado, respectivamente, bem como outros corpos adjacentes a estes já detalhados em outros estudos. Os corpos localizados no extremo norte, incluindo Várzea do Macaco, estão fora da área aqui estudada.

Dados magnéticos e gamaespetrométricos são, usualmente, desmembrados, por meio de transformações e filtros, com o objetivo de obter diferentes facetas dos mesmos dados. A partir do campo magnético total (Figura 5B), foram obtidos o tilt derivativo, sinal analítico e $1^{\text {a }}$ derivada do campo magnético. $\mathrm{O}$ sinal analítico está definido como a magnitude da soma das 3 derivadas direcionais dos corpos magnéticos, servindo como parâmetro na delimitação dos corpos ao recuperar variações angulares nas bordas dos corpos (NABIGHIAN, 1972). A $1^{\mathrm{a}}$ derivada do campo magnético consiste em um filtro passa-alta que remove sinais de alta frequência, com intuito de obter anomalias com bordas mais definidas (ISLES; RANKIN, 2013). $\mathrm{O}$ tilt derivativo é obtido pelo arctan da razão entre $1^{\mathrm{a}}$ derivada e derivada lateral total, resultando em um filtro similar a $1^{\text {a }}$ derivada, porém com informações mais profundas (MILLER; SINGH, 1994). Para os dados de aerogamaespetrometria, são obtidas 3 fontes naturais de radiação gama, frutos do decaimento dos elementos U-Th-K (MINTY, 1997) calibrados, a fim de se obter valores quantificáveis (notação "e" indicando equivalente). Adicionalmente, as respostas radioativas dos elementos são aplicadas às razões entre elementos, para realçar determinados tipos de litologias e a composição ternária RGB, colorindo sinteticamente os valores de vermelho, verde e azul com os valores de potássio, equivalente de tório e equivalente de urânio, respectivamente.

Foram elaborados 13 mapas a partir desses dados (Figuras 4, 5 e 6) e, a partir deles, analisadas, qualitativamente, as respostas magnéticas, gamaespectrométricas e de relevo. Foram estabelecidas as variações do sinal geofísico e descritas a aplicação de cada um para a identificação e delimitação dos corpos ultramáficos, avaliando a eficácia dos mesmos como parâmetros prospectivos. A tabela 1 compila os resultados.

\section{RESULTADOS E DISCUSSÃO}

A área de estudo (Figura 4) está localizada no norte do Estado da Bahia, no município de Andorinha, a cerca de $420 \mathrm{~km} \mathrm{de}$ Salvador. A imagem de satélite demonstra um relevo plano na área, sem texturas indicativas, diferentemente dos terrenos graníticos adjacentes localizados à Oeste.

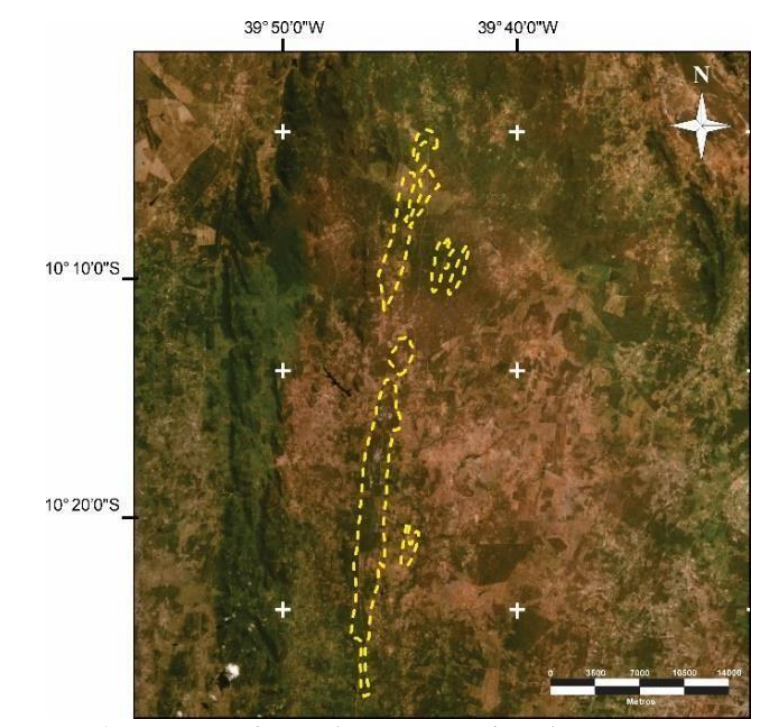

Figura 4 - Imagem de satélite mostrando relevo suave na área de estudo, sem feições geomorfológicas significativas. Imagem de satélite extraída de ESRI (2021) e delimitação das áreas com corpos máfico-ultramáficos de Costa et al. (2014).

Os dados de suscetibilidade magnética da área de estudo revelam resultados heterogêneos na identificação do Complexo Jacurici. A Figura 5 apresenta os mapas para: (1) tilt derivativo do campo magnético total; (2) campo magnético total; (3) sinal analítico do campo magnético total; (4) $1^{a}$ derivada do campo magnético total. A interação tilt derivativo apresenta valores altos a intermediários para os segmentos, demonstrando valores superiores, em especial nos setores a norte (Figura 5A). Adicionalmente, esse filtro identifica lineamentos de sentido N-S na área de estudo. O campo magnético total (Figura 5B) ilustra os lineamentos da área de estudo, porém não retorna qualquer tipo de anomalia ou variação dos valores magnéticos para os corpos. O filtro sinal analítico para o campo magnético total (Figura 5C) retorna atributos positivos na identificação dos corpos, apresentando valores altos e com boa delimitação, especialmente para a área Sul. No entanto, os mapas gerados apresentam respostas magnéticas similares para os conjuntos de rochas laterais à área de interesse, limitando sua eficácia. O filtro da $1^{\text {a }}$ derivada do campo magnético total (Figura 5D) demonstra 
satisfatoriamente as estruturas regionais, porém não descreve os corpos sob nenhum aspecto.

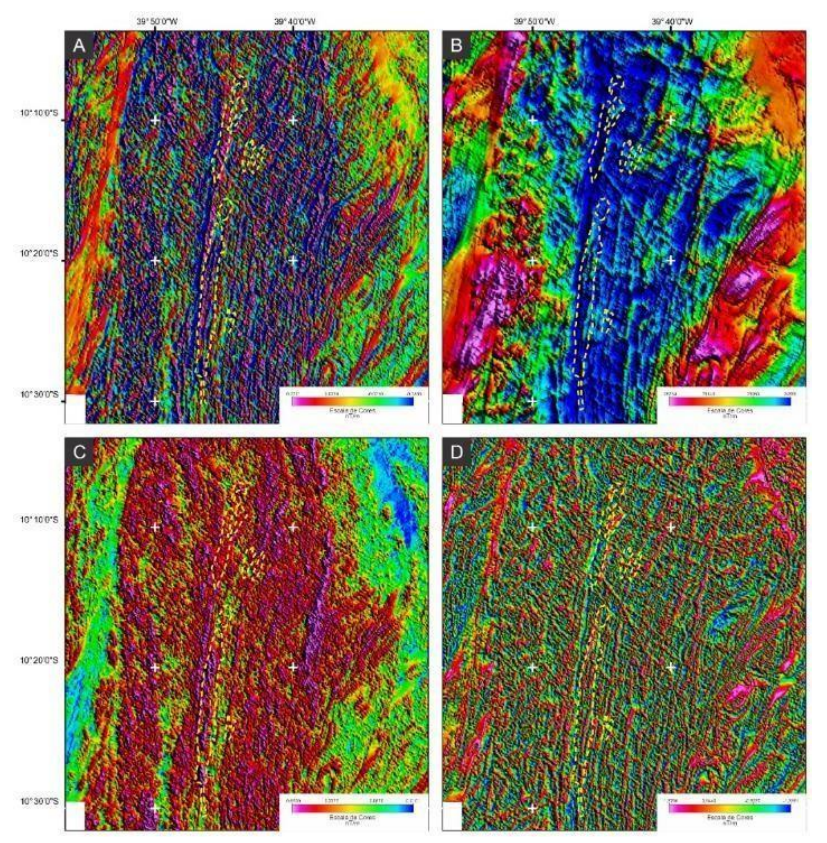

Figura 5 - Mapas de suscetibilidade magnética para região do Vale do Jacurici, demonstrando as anomalias magnéticas para as interações do tipo (A) Tilt derivativo do campo magnético total; (B) Campo magnético total; (C) Sinal analítico do campo magnético total; (D) $1^{a}$ derivada do campo magnético total.

Os dados de gamaespectrometria na área de estudo apresentam respostas variadas para os seguintes filtros: (1) eU, (2) eTh, (3) K, (4) total, (5) eU/eTh, (6) eU/K, (7) eTh/K e (8) ternário. O elemento $\mathrm{K}$ (Figura 6A) apresenta uma forte anomalia relacionada ao complexo alcalino Itiúba, lateral à área de estudo, limitando o potencial do elemento na identificação do corpo mineralizado. O elemento eU (Figura 6B) é caracterizado por baixo teor, não apresentando qualquer tipo de anomalia na área dos corpos, apenas demonstrando, de forma incipiente, o lineamento regional. O elemento Th (Figura 6C) apresenta valores de intermediário a alto, na forma de estruturas N-S consistentes e boa demarcação dos corpos, em especial nos corpos à Norte. A contagem total (Figura 6D) demonstra um comportamento similar ao $\mathrm{K}$, apresentando valores intermediários na parte Norte e baixos no Sul. Apesar da grande anomalia do Complexo Itiúba, é possível delimitar os corpos ao norte. A razão eU/eTh (Figura 6E) apresenta valores intermediários, com delimitação parcial dos corpos, porém demonstra o lineamento N-S. O canal eU/K (Figura 6F) apresenta valores intermediários para a área, apresentando boa diferenciação em relação ao background, porém com limitada capacidade de identificação dos limites dos corpos. O canal eTh/K (Figura 6G) apresenta satisfatoriamente o lineamento N-S, com boa diferenciação dos corpos ao background, em especial na área Sul. Para a composição RGB (Figura 6H), os corpos não apresentam diferenciação em relação ao background.

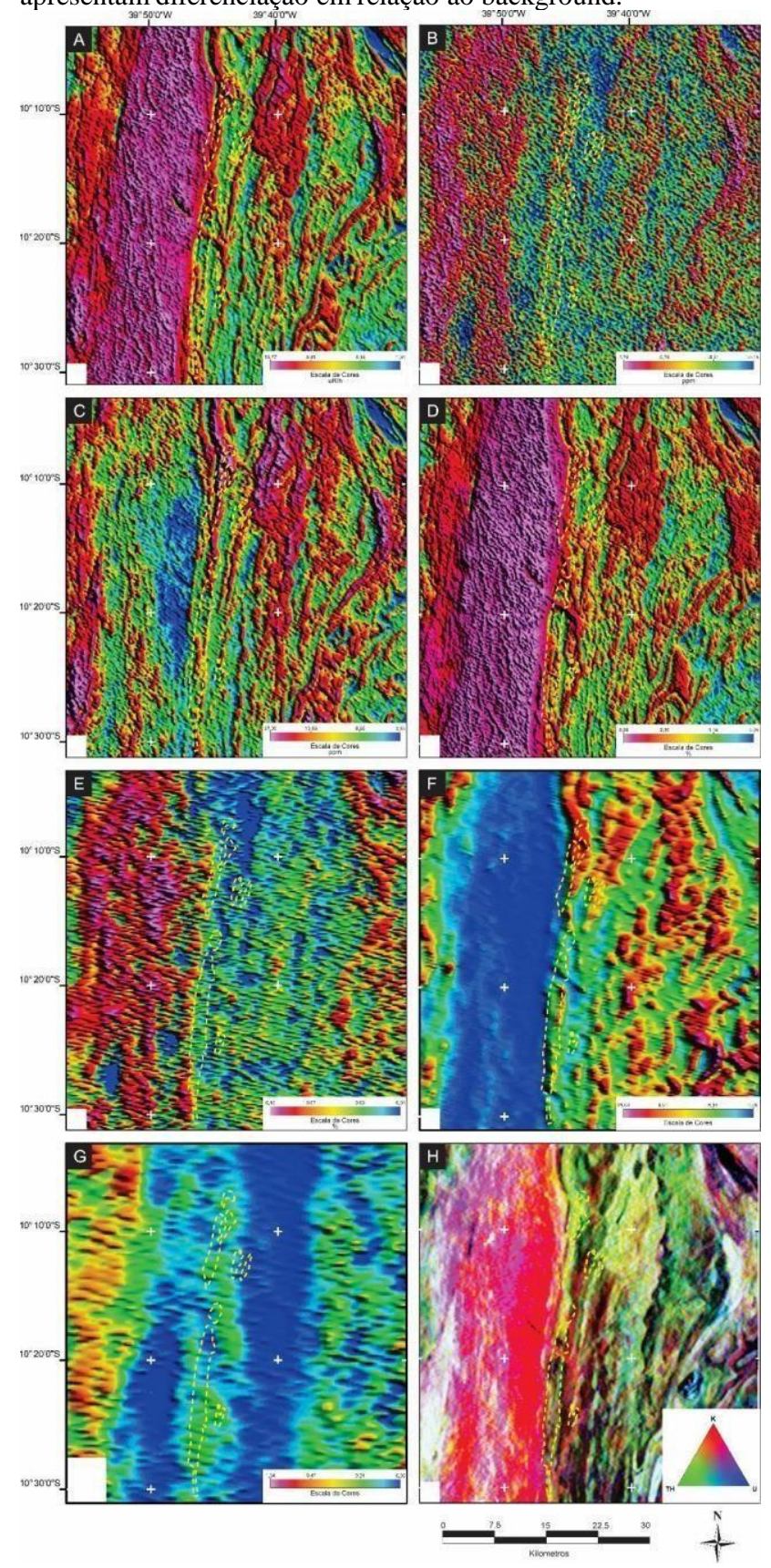

Figura 6 - Mapas de gamespectrometria para região do Vale do Jacurici, demonstrando as anomalias radiométricas para A) Teor de K (\%); B) Teor de U (ppm); C) Teor de Th (ppm); D) Valores da contagem total; E) razão eU/eTh; F) razão eU/K; G) razão eTh/K; H) composição ternária $R G B$ com os valores de $U$, The $K$. 
A tabela 1 compila os resultados apresentados para cada sensor remoto, apresentando uma descrição simplificada, a variação dos valores encontrados (nTm-1 para o sinal magnético e \% e ppm para gamaespectrometria) e a eficácia destes na identificação e delimitação dos segmentos com abundantes corpos máfico-ultramáficos do Complexo do Jacurici.

Tabela 1- Compilação de respostas de sensoriamento remoto nas áreas com corpos mineralizados (dados de 1- Banco de dados ESRI; 2 e 3 -Levantamentos geofísicos da CPBM).

\begin{tabular}{|c|c|c|c|c|}
\hline & Sensor Remoto & Descrição & Variação & Eficácia \\
\hline $\begin{array}{l}\text { Relevo e } \\
\text { geomorfologia }\end{array}$ & Imagem de satélite $^{1}$ & $\begin{array}{c}\text { Baixo relevo sem protuberâncias } \\
\text { ou texturas indicativas }\end{array}$ & - & Baixa \\
\hline \multirow{4}{*}{$\begin{array}{l}\text { Anomalia } \\
\text { Magnética }\end{array}$} & Tilt derivativo $^{2}$ & $\begin{array}{l}\text { Demonstra o lineamento N-S, no } \\
\text { entanto provem pouca } \\
\text { informação para delimitação dos } \\
\text { segmentos }\end{array}$ & $\begin{array}{l}\text { entre }-1.3 \text { e } \\
1.3 \mathrm{nT} / \mathrm{m}\end{array}$ & Média \\
\hline & Sinal Analitico ${ }^{2}$ & $\begin{array}{c}\text { Sinal positivo na área do } \\
\text { segmento, ilustrando } \\
\text { alongamento N-S, delimitando } \\
\text { bem a extensão do corpo. } \\
\text { Resultados similares são } \\
\text { encontrados em corpos graníticos } \\
\text { laterais, limitando potencial } \\
\text { exploratório regional } \\
\end{array}$ & $\begin{array}{l}\text { entre } 0.24 \text { e } \\
0.44 \mathrm{nT} / \mathrm{m}\end{array}$ & Alta-média \\
\hline & $1^{\text {a }}$ derivada $^{2}$ & $\begin{array}{c}\text { Demonstra o lineamento N-S e } \\
\text { anomalia nos segmentos a Norte, } \\
\text { porém com distribuição } \\
\text { heterogênea }\end{array}$ & $\begin{array}{l}\text { entre }-0.2 \text { e } \\
0.2 \mathrm{nT} / \mathrm{m}\end{array}$ & Baixa \\
\hline & Campo magnético total ${ }^{2}$ & $\begin{array}{l}\text { Resposta magnética baixa, com } \\
\text { baixo grau de lineamento e } \\
\text { estruturação reconhecida }\end{array}$ & $\begin{array}{l}\text { entre } 2489 \text { e } \\
25053 \mathrm{nT} / \mathrm{m}\end{array}$ & Baixa \\
\hline \multirow{8}{*}{$\begin{array}{l}\text { Gamaespectromet } \\
\text { ria }\end{array}$} & $\mathrm{eU}^{3}$ & $\begin{array}{c}\text { Baixa concentração do elemento } \\
\text { produz resultados pouco } \\
\text { significativos }\end{array}$ & $\begin{array}{l}\text { entre }-0.15 \text { e } \\
0.4 \text { ppm }\end{array}$ & Baixa \\
\hline & $\mathrm{eTh}^{3}$ & $\begin{array}{l}\text { Teores altos, identificando } \\
\text { lineamento e delimitando os } \\
\text { corpos, porém com resposta } \\
\text { heterogênea }\end{array}$ & $\begin{array}{l}\text { entre } 9 \text { e } 27 \\
\text { ppm }\end{array}$ & Média-baixa \\
\hline & $\mathrm{K}^{3}$ & $\begin{array}{l}\text { Teores intermediários, } \\
\text { identificando lineamento e } \\
\text { delimitando os corpos } \\
\text { parcialmente, porém com } \\
\text { resposta heterogênea devido aos } \\
\text { corpos graníticos laterais que } \\
\text { dificultam a definição }\end{array}$ & $\begin{array}{l}\text { entre } 1.2 \mathrm{e} \\
\quad 3.0 \%\end{array}$ & Média-baixa \\
\hline & Total $^{3}$ & $\begin{array}{c}\text { Resposta relativamente forte, } \\
\text { com segmentos definidos ao } \\
\text { Norte, porém com respostas } \\
\text { heterogêneas }\end{array}$ & $\begin{array}{l}\text { entre } 5 \text { e } 10 \\
\text { uR/h }\end{array}$ & média \\
\hline & $\mathrm{eU} / \mathrm{eTh}^{3}$ & $\begin{array}{c}\text { Razões intermediárias } \\
\text { homogêneas, porém, com } \\
\text { limitada capacidade de } \\
\text { delimitação dos segmentos }\end{array}$ & $\begin{array}{l}\text { ao redor de } \\
0.4\end{array}$ & Média-baixa \\
\hline & $\mathrm{eU} / \mathrm{K}^{3}$ & $\begin{array}{l}\text { Razões intermediárias } \\
\text { homogêneas, com capacidade de } \\
\text { delimitação dos segmentos }\end{array}$ & $\begin{array}{l}\text { ao redor de } \\
\quad 24\end{array}$ & Média-alta \\
\hline & $\mathrm{Th} / \mathrm{K}^{3}$ & $\begin{array}{c}\text { Razões intermediárias } \\
\text { homogêneas, com melhor } \\
\text { identificação dos segmentos }\end{array}$ & entre 5 e 10 & Média-alta \\
\hline & Ternário $^{3}$ & $\begin{array}{l}\text { Resposta heterogênea, com } \\
\text { baixo potencial delimitação dos } \\
\text { segmentos }\end{array}$ & $\begin{array}{l}\text { valores } \\
\text { intermediários } \\
\text { entre U, Th e } \\
\text { K }\end{array}$ & Baixa \\
\hline
\end{tabular}


GALBRAITH e SAUNDERS (1983) apresentam a distribuição dos elementos medidos pela gamaespectrometria em rochas, identificando valores ao redor de $7 \mathrm{ppb}$ para U, $20 \mathrm{ppb}$ para Th e $0.01 \%$ para K para rochas ígneas ultrabásicas, similar a outros depósitos encontrados no Brasil como o Complexo Morro Feio (SILVA; DUQUE; ALVES, 2019). Os corpos graníticos alcalinos da região do Jacurici, em especial o Sienito Itíuba, tendem a dominar as anomalias positivas da gamaespetrometria, em especial no canal de K. Anomalias dessa magnitude podem mascarar efeitos de corpos de dimensões menores, como os do Complexo Jacurici. O alto contraste entre o Sienito Itiúba e o embasamento torna pouco claro os teores baixos de $\mathrm{K}$ e $\mathrm{U}$ no Complexo Jacurici produzindo um sinal que indistinto em relação ao background local. A resolução dos sensores geofísicos e baixa extensão areal dos corpos máfico-ultramáfico do Jacurici impõe incertezas nos sinais encontrados. Entretanto, SILVA, DUQUE e ALVES (2019) caracterizam o Complexo Ultramáfico Morro Feio como delimitado pelas razões K/Th e U/Th. Resultado similar também foi observado nas áreas com ocorrência de corpos do Complexo Jacurici. Desta forma, estes parâmetros podem ser considerados como uma ferramenta auxiliar na delimitação de terrenos de maior interesse prospectivo. Adicionalmente, as variações nos resultados das áreas Norte e Sul podem indicar variações na geologia local, possivelmente em rochas de embasamento.

Em resumo, é possível verificar a maior eficiência dos métodos tilt derivativo e sinal magnético no levantamento de suscetibilidade magnética e eTh/K, eU/eTh3, e U/K nos dados de gamaespectrometria como um método local combinado para delimitação do áreas com corpos máfico-ultramáfico do Complexo Jacurici, constituindo os parâmetros mais apropriadas para prospecção regional quando utilizado estes sensores.

\section{CONCLUSÕES}

O estudo caracteriza as respostas geofísicas e de relevo dos corpos máfico-ultramáficos do Vale do Jacurici, através dos atributos petrofísicos de suscetibilidade magnética e gamaespectrometria. Foram gerados 13 mapas da área de estudo, através de sensores remotos supracitados e, posteriormente, foi elaborada uma tabela com os atributos encontrados. Os dados encontrados mostram que: (1) informações de relevo e de geomorfologia baseadas em imagens áreas apresentam pouco resultado para os corpos; (2) as interações tilt magnético e sinal analítico demonstram o maior potencial para identificação e delimitação dos segmentos com corpos, devido aos valores altos e destacados em relação ao background; (3) as razões eTh/K, eU/eTh, eU/eK, apresentam os melhores resultados para a área que hospeda os corpos podendo ser útil para prospecção. Adicionalmente, os resultados sugerem que o segmento localizado ao norte apresenta variações nas respostas geofísicas em relação ao segmento sul, como demonstrado nas Figuras 5B e $\mathrm{C}$ e 6. A identificação e delimitação de áreas similares que hospedem corpos deve ser feita utilizandoum conjunto de sensores remotos, como os utilizados neste trabalho, a fim de eliminar ruídos e diferenciar as áreas de interesse do background.

\section{REFERÊNCIAS}

BARBOSA DE DEUS, P.; VIANA, J.D.S. Jacurici valley chromite district. In: , 1982, Salvador. INTERNATIONAL. SYMPOSIUM ON ARCHEAN AND EARLY PROTEROZOIC GEOLOGIC EVOLUTION AND METALLOGENESIS. Salvador: [s. n.], 1982. p. 97-107.

BARBOSA, J.S.F.; SABATÉ, P. Paleoproterozoic collage of Archean plates of the São Francisco Craton in Bahia. Rev Bras Geoc, [s. l.], v. 33, n. 1, p. 7-14, 2003.

CLARK, T. Oxide minerals in the Turnagain ultramafic complex, northwestern British Columbia. Canadian Journal of Earth Sciences, [s. l.], v. 15, n. 12, p. 1893-1903, 1978. Disponível em: https://doi.org/10.1139/e78-201

COSTA, I.G.V. Carta Geológica Preliminar - Folhas Andorinha (SC.24-Y-B-II) e Pinhões (SC.24-V-D-V). Salvador: [s. n.], 2014.

DIAS, J.R.V.P. et al. O corpo Várzea do Macaco e as mineralizações de cromo, níquel e cobre, Complexo Máficoultramáfico Jacurici, Cráton São Francisco, Bahia. Brazilian Journal of Geology, [s. l.], v. 44, n. 2, p. 289-308, 2014. Disponível em: https://doi.org/10.5327/Z23174889201400020009. Acesso em: 30 jan. 2021.

FILHO, C.R.S. et al. Spatial analysis of airborne geophysical data applied to geological mapping and mineral prospecting in the Serra Leste Region, Carajás Mineral Province, Brazil. Surveys in Geophysics, [s. l.], v. 28, n. 5-6, p. 377-405, 2007. Disponível em: https://doi.org/10.1007/s10712-0089031-5

FRIEDRICH, B.M. et al. Petrogenesis of the massive chromitite layer from the Jacurici Complex, Brazil: evidence from inclusions in chromite. Mineralium Deposita, [s. l.], v. 55, n. 6, p. 1105-1126, 2020. Disponível em: https://doi.org/10.1007/s00126-019-00917-0. Acesso em: 7 jan. 2021.

IRVINE, T. N. CHROMIAN SPINEL AS A PETROGENETIC INDICATOR: PART 2. PETROLOGIC APPLICATIONS. Canadian Journal of Earth Sciences, [s. l.], v. 4, n. 1, p. 71103, 1967. Disponível em: https://doi.org/10.1139/e67-004

ISLES, D.J.; RANKIN, L.R. Geological Interpretation of

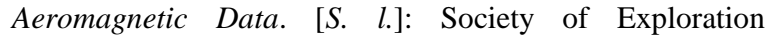
Geophysicists and Australian Society of Exploration Geophysicists, 2013. Disponível em: https://doi.org/10.1190/1.9781560803218. Acesso em: 19 abr. 2021.

KARLSEN, T.A.; OLESEN, O. Airborne geophysical prospecting for ultramafite associated talc, Altermark, northern Norway. Journal of Applied Geophysics, [s. l.], v. 35, n. 4, p. 215-236, 1996. Disponível em: https://doi.org/10.1016/0926-9851(96)00026-2

KOLELI, N.; DEMIR, A. Chromite. In: ENVIRONMENTAL 
MATERIALS AND WASTE: RESOURCE RECOVERY AND POLLUTION PREVENTION. [S. l.]: Elsevier Inc., 2016. p. 245-263. Disponível em: https://doi.org/10.1016/B978-0-12-803837-6.00011-1

KOSIN, M. et al. Guia De Excursão - Geologia Do Segmento Norte Do Orógeno Itabuna-Salvador-Curaçá. Revista Brasileira de Geociências, [s. l.], v. 33, n. 1, p. 27-32, 2003. Disponível em: https://doi.org/10.25249/0375$7536.200333 s 12732$

LASA, Prospecções. Projeto Levantamento Aerogeofísico da Área Riacho Seco-Andorinha, Relatório final. Rio de Janeiro: SICM/CBPM, 2002.

MARINHO, M.M. et al. Geologia e potencial cromitífero do Vale do Jacurici-Bahia. In: XXXIV CONGRESSO BRASILEIRO DE GEOLOGIA. GOIÂNIA. [S. l.: s. $n$.], 1986. p. 2074-2088.

MARQUES, J. C. et al. Re-Os and Sm-Nd isotope and trace element constraints on the origin of the chromite deposit of the Ipueira-Medrado Sill, Bahia, Brazil. Journal of Petrology, [s. l.], v. 44, n. 4, p. 659-678, 2003. Disponível em: https://doi.org/10.1093/petrology/44.4.659. Acesso em: 30 jan. 2021.

MARQUES, J.C. et al. Thick chromitite of the Jacurici Complex (NE Craton São Francisco, Brazil): Cumulate chromite slurry in a conduit. Ore Geology Reviews, [s. l.], v. 90, p. 131-147, 2017. Disponível em: https://doi.org/10.1016/j.oregeorev.2017.04.033. Acesso em: 30 jan. 2021.

MARQUES, J.C.; FILHO, C.F.F. The Chromite Deposit of the Ipueira-Medrado Sill, Sao Francisco Craton, Bahia State, Brazil. Economic Geology, [s. l.], v. 98, n. 1, p. 87-108, $2003 . \quad$ Disponível em: https://doi.org/10.2113/gsecongeo.98.1.87. Acesso em: 30 jan. 2021.

MILLER, H.G.; SINGH, V. Potential field tilt-a new concept for location of potential field sources. Journal of Applied Geophysics, [s. l.], v. 32, n. 2-3, p. 213-217, 1994. Disponível em: https://doi.org/10.1016/09269851(94)90022-1

MINTY, B. R.S. Fundamentals of airborne gamma-ray spectrometry. AGSO Journal of Australian Geology and Geophysics, [s. l.], v. 17, n. 2, p. 39-50, 1997.

MISI, A. et al. Principais Domínios Metalogéneticos. Ouro do Greenstone Belt do Rio Itapicuru. Companhia Baiana de Pesquisa Mineral, Texto Explicativo., Salvador, v. 1, n. 1, p. 109-126, 2012.

NABIGHIAN, M.N. The analytic signal of two-dimensional magnetic bodies with polygonal cross-section: Its properties and use for automated anomaly interpretation. Geophysics, [s. l.], v. 37, n. 3, p. 507-517, 1972. Disponível em: https://doi.org/10.1190/1.1440276
OLIVEIRA, E.P.; CARVALHO, M.J.; MCNAUGHTON, N.J. Evolução do segmento norte do orógeno Itabuna-SalvadorCuraçá: cronologia da acresção de arcos, colisão continental e escape de terrenos. Geologia USP. Série Científica, [s. l.], v. 4, n. 1, p. 41-53, 2004. Disponível em: https://doi.org/10.5327/S1519-874X2004000100003. Acesso em: 30 jan. 2021.

OLIVEIRA, E. P.; MCNAUGHTON, N. J.; ARMSTRONG, R. Mesoarchaean to Palaeoproterozoic growth of the northern segment of the Itabuna-Salvador-Curaçá orogen, São Francisco craton, Brazil. Geological Society, London, Special Publications, [s. l.], v. 338, n. 1, p. 263-286, 2010. Disponível em: https://doi.org/10.1144/SP338.13. Acesso em: 30 jan. 2021.

SEPLAN, Secretaria do Planejamento do Estado da Bahia. Diálogos territoriais II: Piemonte Norte do Itapicuru. [S. l.: s.n.], 2013.

SILVA, A.B.; DUQUE, T.R.F.; ALVES, F.M. Interpretation of radiometric ratios and magnetic anomalies from Morro Feio ultramafic complex, central-western Brazil. Revista Brasileira de Geofisica, [s. l.], v. 37, n. 3, p. 309-324, 2019. Disponível em: https://doi.org/10.22564/rbgf.v37i3.2010

SILVEIRA, C.J.S. et al. Geocronologia U-Pb em zircão de rochas intrusivas e de embasamento na Região do Vale do Jacurici, Cráton do São Francisco, Bahia. Brazilian Journal of Geology, [s. l.], v. 45, n. 3, p. 453-474, 2015. Disponível em: https://doi.org/10.1590/2317-488920150030233. Acesso em: 7 jan. 2021.

TEIXEIRA, J.B.G. et al. Depósitos de cobre do Vale do Rio Curaçá, Bahia. In: R.S.C., Brito; M.G., Silva; R.M, Kuyumijan (org.). São Paulo: modelos de depósitos de cobre no Brasil e sua resposta ao intemperismo. Brasília, Serviço Geológico do Brasil. [S. l.: s. n.], 2010. p. 218.

TUKIAINEN, T.; THORNING, L. Detection of kimberlitic rocks in West Greenland using airborne hyperspectral data: The HyperGreen 2002 project. Geological Survey of Denmark and Greenland Bulletin, [s. l.], v. v. 7, n. 7, p. 69-72, 2005. Disponível em: https://doi.org/10.34194/geusb.v7.4845

VAN DER MEER, F.; LIHUI, F.; BODECHTEL, J. MAIS imaging spectrometer data analysis for $\mathrm{Ni}-\mathrm{Cu}$ prospecting in ultramafic rocks of the Jinchuan group, China. International Journal of Remote Sensing, [s. l.], v. 18, n. 13, p. 2743-2761, $1997 . \quad$ Disponível em: https://doi.org/10.1080/014311697217314

\section{AGRADECIMENTOS}

O autor agradece a Universidade Federal do Rio Grande do Sul pela infraestrutura nas análises e ao Conselho Nacional Científico de Pesquisa (CNPQ) pela bolsa de estudo. Agradecemos a Mineração Vale do Jacurici (Grupo FERBASA) e seus colaboradores pelo constante apoio as nossas atividades de pesquisa. J. Dias é bolsista do Conselho Nacional de Pesquisa 
(CNPq), projeto 140565 / 2014-0 e este estudo faz parte de sua tese de doutorado desenvolvida no Programa de Pós-graduação em Geociências (PPGGeo) do Instituto de Geociências, Universidade Federal do Rio Grande do Sul (IGEO / UFRGS) aos quais agradece pelo suporte. $\mathrm{O}$ CNPq também é agradecido por J. Marques pela concessão de recursos para o projeto através do edital universal MCTIC/CNPq n. ${ }^{\circ}$ 28/2018 (436963 / 2018-3) e bolsa de produtividade em pesquisa edital CNPq n. ${ }^{\circ}$ 28/2018 (309519 / 2018-7). Gabriel Bertolini agradece a CAPES pela bolsa de pós-doutorado (CAPES PrInt - 88887.310123/2018-00).

Recebido em: 31/03/2021

Aceito para publicação em: 20/06/2021 